\title{
ENTRE TRAJETÓRIAS E ESTRATÉGIAS DE VIDA: A IMPORTÂNCIA DO PROGRAMA NACIONAL DE CRÉDITO FUNDIÁRIO NO ACESSO À TERRA PELA JUVENTUDE RURAL NO ESTADO DO ESPÍRITO SANTO'
}

\author{
BETWEEN PATHS AND LIFE STRATEGIES: THE \\ IMPORTANCE OF THE PROGRAMA NACIONAL DE \\ CRÉDITO FUNDIÁRIO ON ACCESS TO LAND BY RURAL \\ YOUTH IN THE STATE OF ESPÍRITO SANTO
}

\author{
Celia Jaqueline Sanz Rodriguez
}

Universidade Federal do Rio Grande do Sul - Porto Alegre - RS - Brasil

\section{Marcelo Antonio Conterato}

Universidade Federal do Rio Grande do Sul - Porto Alegre - RS - Brasil

\begin{abstract}
Resumo: Qual a importância e o significado que assume a terra entre os jovens beneficiários do Programa Nacional de Crédito Fundiário - PNCF? Em termos gerais, é essa a pergunta que este paper procura responder ao entrevistar os jovens rurais que acessaram o PNCF no Estado do Espírito Santo. As opções teóricas adotadas neste artigo e as narrativas dos jovens entrevistados permitiu perceber que diferentes trajetórias e condições de vida orientam e dão diferentes significados à própria condição de acesso de acesso à terra e possibilidades de permanência no campo. Por outro lado, e perpassado pelos significados atribuídos à condição de posse e propriedade da terra, o acesso ao PNCF se enquadra enquanto estratégias de escolha e adaptação ou de reação e necessidade. Para a realização da pesquisa, foram entrevistadas sete associações de jovens rurais, em dois municípios com maior número de projetos dentro do selo Nossa Primeira Terra - NPT do PNCF, no Estado do Espírito Santo. As entrevistas permitiram concluir que o acesso à terra representa a possibilidade dos jovens permanecerem no campo.
\end{abstract}

Palavras-chave: Juventude rural. Agricultura familiar. Estratégias.

\footnotetext{
1 Uma primeira versão deste trabalho foi apresentada no $53^{\circ}$ Congresso da Sociedade Brasileira de Economia, Administração e Sociologia Rural, realizado em João Pessoa (PB), 2015.
} 


\begin{abstract}
Which is the importance and meaning that has the land to the young beneficiaries of the Programa Nacional de Crédito Fundiário - PNCF ("national program for land credit")? This is the question that this paper seeks to answer when interviewing rural youth who accessed the PNCF in the state of Espirito Santo - Brazil. The theoretical approach adopted in this article and the narratives of young people interviewed allowed perceiving different trajectories and living conditions that guide and give different meanings to their condition to access the land and their possibilities to continue in the countryside. On the other hand, also with the feeling of the meaning attributed the condition of possession and ownership of land, the access to governmental credit (PNCF) fits as strategies of choice and adaptation, or reaction and need. For this research seven rural youth associations in two small country towns were interviewed with the highest number of projects within the seal Nossa Primeira Terra NPT ("our first land") of PNCF in the state of Espirito Santo. The interviews showed that access to land is the key factor of young people to remain in the field.

Keywords: Rural youth. Family farming. Strategies.
\end{abstract}




\title{
1 Introdução
}

Qual a importância e o significado que assume a terra entre os jovens ${ }^{2}$ beneficiários do PNCF? Qual a importância e a relação do programa com a permanência dos jovens no meio rural? Qual o significado do acesso à terra e quais as reações estratégicas dos jovens? Basicamente, são estas perguntas que norteiam este estudo que teve como premissa metodológica a perspectiva orientada aos atores e às estratégias de diversificação dos meios de vida (livelihoods).

A discussão em torno dos problemas do êxodo rural seletivo que, no Brasil configura-se com o envelhecimento e a masculinização do campo, tem-se colocado com forte ênfase enquanto uma questão para o próprio desenvolvimento rural do país, obrigando amplos setores da sociedade a se debruçarem sobre o problema. Por que os jovens abandonam o campo? O que poderia mudar essa estratégia?

FROEHLICH et al. (2011) apontam que os jovens e as mulheres continuam migrando para as cidades, pois estas se apresentam como mais promissoras e atraentes que o meio rural. Para Camaro e Abramovay (1997), no entanto, as explicações para o êxodo seletivo também podem ser encontradas nas próprias realidades rurais, nas quais os mais jovens apresentam pouco capital, pouca terra e pouco trabalho, vendo na emigração uma estratégia de melhoria de vida. A questão do precário acesso à terra é apontada também no estudo realizado por Castro et al. (2013), no qual a justificativa dada pelos jovens quanto à emigração converge para o mesmo problema.

A argumentação de Wanderley (2007) perpassa as mesmas considerações do parágrafo anterior, levantando justamente a questão da estrutura de distribuição da terra entre os camponeses

\begin{abstract}
a estrutura de distribuição da terra é a responsável maior pelo bloqueio à reprodução social dos pequenos agricultores camponeses das áreas estudadas, na medida em que impõe profundas restrições à capacidade produtiva do estabelecimento, inibe as possibilidades de ocupação da força de trabalho dos próprios membros da família e, em
\end{abstract}

\footnotetext{
2 Em relação à categoria social de juventude rural há uma vasta discussão sobre o tema. Não incluímos esta discussão no artigo por estarmos utilizando a idade limite (entre 18 e 29 anos) apresentada nos critérios do próprio PNCF e do selo NPT.
} 
consequência, provoca nos jovens a necessidade de migração (WANDERLEY, 2007, p. 24).

Dentro desse cenário e para responder nossa indagação, realizamos um estudo nos municípios capixabas com maior número de projetos de PNCF com o selo NPT. Os municípios selecionados foram Águia Branca e Barra de São Francisco, ambos localizados na mesorregião noroeste do Estado do Espírito Santo ${ }^{3}$. Em termos gerais, esses municípios apresentam características similares em muitos aspectos: baixos índices de Índice de Desenvolvimento Humano - IDH (0,69 Águia Branca e 0,701 Barra de São Francisco), predomínio da agricultura familiar desenvolvida em pequenos estabelecimentos rurais, prolongados períodos de estiagem, pouca fertilidade dos solos e produtividade baixa das duas principais atividades agropecuárias desenvolvidas - café e pecuária leiteira, baixo dinamismo econômico e pouca diversidade agrícola e econômica.

Figura 1. Mapa do Estado do Espírito Santo, com destaque para os municípios de Águia Branca e Barra de São Francisco

\footnotetext{
3 Instituto Brasileiro de Geografia e Estatística (IBGE).
} 


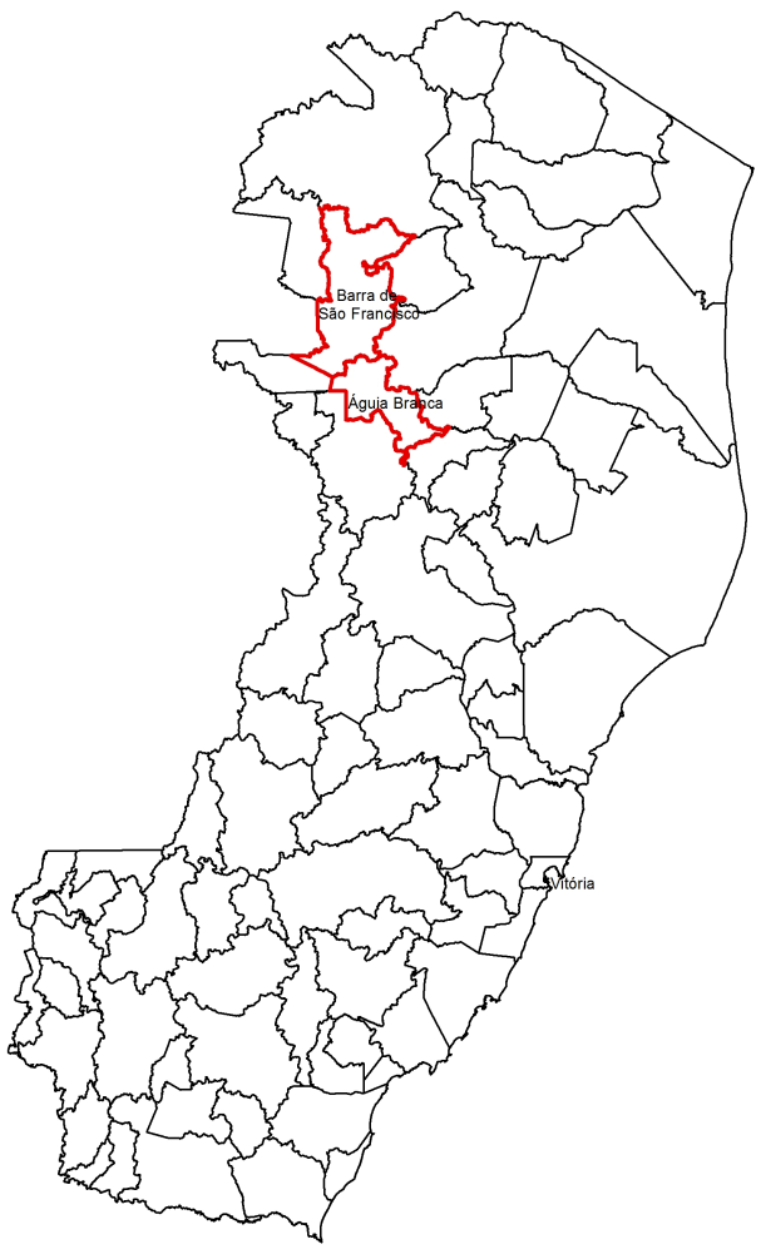

Fonte: Geobases. Ferrari, F. 2016.

O PNCF consiste num programa de financiamento reembolsável para compra de terra por agricultores familiares, conhecido como modelo de aquisição de terras por mercado4. O programa foi criado em 2003 em substituição ao Programa Banco da Terra, concebido em 1997.

Em termos gerais, o PNCF5 tem como objetivo "contribuir para a redução da pobreza rural e a consolidação da agricultura familiar para

\footnotetext{
4 Segundo Lima (2011) no Brasil coexistem dois modelos de Reforma Agrária: o modelo tradicional, caracterizado pela desapropriação de terras consideradas improdutivas e o modelo de reforma agrária por mercado. Este último foi inspirado a partir de um documento publicado pelo Banco Mundial, em 1975, denominado "Land Reform Policy Paper", no qual aparecem recomendações para a questão da reforma agrária a partir de compras de terra no mercado.

$5 \mathrm{O}$ arranjo institucional para a implementação do programa segue um modelo de descentralização com a participação do Ministério de Desenvolvimento Agrário (MDA); Unidade Técnica Estadual (UTE); Conselhos de Desenvolvimento Rural (municipal e estadual); redes de apoio (ONG, Sindicatos, Empresas públicas e privadas de ATER) e
} 
melhoria da qualidade de vida, mediante o acesso à terra e o aumento da renda dos trabalhadores rurais sem terra ou com pouca terra" (BRASIL/MDA, 2013, p. 4).

Existem atualmente três linhas de financiamento: a linha Combate à Pobreza Rural - CPR, a linha Consolidação da Agricultura Familiar CAF e o Nossa Primeira Terra - NPT. Basicamente, o que as diferencia são os critérios de elegibilidade e financiamento. A primeira tem como critério atender os agricultores com menor renda per capita 6 e o NPT se destina aos jovens rurais com idade entre 18 e 29 anos, agricultores, filhos de agricultores e/ou jovens formados em escolas agrotécnicas.

De forma específica e segundo os implementadores do programa, o NPT foi pensado para que os jovens tenham acesso à terra e, desta forma, permaneçam no campo e executem seus projetos de vida7. Até 2013, o NPT era um selo especial que garantia aos jovens que se enquadravam em uma das duas linhas até então existentes (CPR e CAF) um bônus de $R \$ 1.000,00$. A partir de 2013 , no entanto, torna-se uma linha específica, com regras, juros e bônus específicos.

$O$ estudo de Castro et al (2013) apontou que $84 \%$ dos jovens entrevistados em sua pesquisa desejavam permanecer no campo, tendo como razão para essa escolha "ter terra para continuar na agricultura. (

agentes financeiros. Cada uma destas instituições tem participações diferentes. Para mais informações, consultar o Manual de Operações, 2013.

O processo para a aquisição da terra se inicia com o requerimento dos próprios interessados e a elaboração de uma proposta de financiamento feita por uma instituição de Assistência Técnica e Extensão Rural (ATER) participante do programa como rede de apoio. Essa proposta é composta basicamente por dois subprojetos: o subprojeto de aquisição de terra (SAT) e o subprojeto de investimento comunitário (SIC) que consiste em infraestrutura básica e produtiva.

Elaborado o projeto e compostos todos os documentos, este passa pela apreciação do Conselho Municipal de Desenvolvimento Rural Sustentável (CMDRS) que analisa a elegibilidade dos beneficiários e do projeto de uma forma geral. A segunda fase é a análise da Unidade Técnica Estadual (UTE) que organiza a documentação e analisa a elegibilidade do imóvel. Por último a proposta é encaminhada ao Conselho Estadual de Desenvolvimento Rural Sustentável (CEDRS) que avalia e delibera sobre a proposta como um todo. Após encerrado esse processo e tendo sido aprovado, o recurso é liberado pelo agente financeiro.

${ }^{6} \mathrm{Em}$ anexo, foi elaborado um quadro com as principais informações e diferenças entre as duas linhas de crédito e o selo NPT.

7 São essas as expressões encontradas em documentos oficiais do MDA e também em instituições como sindicatos e ONGs que informam sobre o NPT. 
CASTRO et al, 2013, p. 25). Essa consideração é de suma importância para este estudo, pois nos permite refletir se essas considerações também estão presentes nas narrativas do jovens entrevistados neste estudo e se os mesmos consideram o PNCF elemento importante enquanto mecanismo de aquisição de terra e permanência no campo.

\section{Material e pressupostos teóricos}

O primeiro contato para a realização do projeto foi feito com os operadores do programa, gestores nacionais, estadual e técnicos municipais. Esses contatos permitiram ter acesso a dados referentes ao número de operações, beneficiários, perfil e conhecimento do programa na sua idealização e implementação.

Durante as visitas a campo, os operadores municipais também fizeram parte de diálogos e puderam expor seus argumentos e pontos de vista a respeito do programa. No entanto, as conversas não foram gravadas e não seguiram um roteiro pré-estabelecido.

Com relação aos jovens, foram realizadas sete entrevistas grupais com as associações constituídas para a aquisição de terra via PNCF. Além das entrevistas, foram realizados dez questionários.

Para a escolha dos projetos que fizeram parte do estudo, foram utilizados dois critérios: o primeiro foi identificar os dois municípios no Estado do Espírito Santo com maior número de jovens que tivessem acessado o selo NPT. O outro elemento foi a questão da antiguidade dos projetos $^{8}$, mesclando projetos coletivos e individualizados. Com esses critérios de seleção, foram organizadas as reuniões que contaram com a participação dos integrantes das associações e parentes mais próximos, como cônjuges e pais dos jovens.

O diálogo das reuniões ${ }^{9}$ seguiu um roteiro pré definido, mas não com um método de "perguntas-respostas", pois a proposta era conhecer os pontos de vista, as interpretações e as representações dos atores envolvidos nos processos. Desse modo, procuramos manter uma proposta dialógica, onde importava o que os atores queriam falar, suas narrativas, sua forma de contar a história do projeto e as suas

\footnotetext{
8 Nenhum dos entrevistados tinha menos de cinco anos de projeto.

9 Os diálogos foram gravados, contudo ficou acordado que a identidade dos participantes seria mantida em sigilo.
} 
trajetórias de vida que explicavam os motivos das suas escolhas. Analiticamente, portanto, as entrevistas nos permitiram compreender as trajetórias de vida e as estratégias enfocadas pelos participantes.

Os questionários serviram para conhecer elementos mais objetivos e seguiram temas gerais como: realidade familiar; produção; tecnologia; trabalho e acesso a políticas públicas com o intuito de conhecer como os próprios jovens percebiam ou não a existência de mudança em suas vidas após o PNCF.

Essas perspectivas metodológicas estão articuladas com dois pressupostos teóricos que fazem parte deste estudo e baseiam nossas interpretações acerca das relações estabelecidas entre os atores sociais e as contingências colocadas no seu cotidiano.

Nesse sentido, cremos conveniente apresentar o marco teórico que orienta nossas interpretações e escolhas metodológicas: a perspectiva orientada aos atores e o conceito de estratégias desenvolvido por Frank Ellis.

2.1 A perspectiva Orientada aos atores e a noção de estratégias de diversificação dos meios de vida (livelihoods).

A maior parte dos processos de mudança social no campo são interpretados tendo como base as relações e as consequências da mercantilização e modernização da agricultura. Os maiores índices de êxodo rural no Brasil concentram-se nos períodos das décadas de 1960 a 1980, como constatam Camaro e Abramovay (1997)10. Essas décadas marcam os processos de substituição das importações, crescente urbanização, modernização e mercantilização da agricultura brasileira.

O processo de mercantilização pode ser entendido como um dos muitos elementos que permitiu (e obrigou) uma crescente integração e interação entre pessoas e diferentes grupos sociais, acarretando um processo social de mudança generalizada, mas não necessariamente linear, ininterrupta e homogênea.

Já a modernização da agricultura impulsionou uma série de mudanças sociotécnicas que gerou uma grande transformação na forma

\footnotetext{
10 Como salientam os atores entre as décadas de 1960 a 1980, o êxodo rural brasileiro alcançou 27 milhões de pessoas.
} 
de produzir que, ao externalizar vários processos da produção, inseriu os agricultores num universo de relações sociais, econômicas e mesmo de relações com a natureza que repercutiu gradativamente na redefinição de suas lógicas (práticas, saberes, valores e relações sociais), na reorganização das suas unidades produtivas e numa grande abertura de trocas não só materiais como também simbólicas, que possibilita, entre tantas outras questões, uma maior abertura e interesse pelas "coisas" da cidade.

É, contudo, inserido numa dinâmica territorial ${ }^{11}$ que os processos de mercantilização e a própria modernização estão imersos, não como "camisas de forças" que deixam os agricultores sem capacidade de ação, mas como processos que são envolvidos por uma série de estratégias possíveis dentro daquela dinâmica e para determinados atores e grupos sociais.

Dessa forma, tanto a modernização quanto a mercantilização da agricultura se processam e são processados diferentemente em contextos e situações diversas, tendo, portanto, um papel influente, mas não uma força abrupta externa que se impõe da mesma forma e na mesma intensidade em todas as dinâmicas e segmentos sociais.

Assim, pensar nos processos que envolvem e acarretam mudanças sociais é pensar em processos de "interações, negociações e lutas sociais que ocorrem entre os diversos tipos de atores" (LONG; PLOEG, 2011 , p. 24), sejam eles individuais, coletivos, locais ou externos.

Nesses processos não se pode prever, como pressupunham algumas teorias, um resultado único e linear. Pelo contrário, os resultados em termos de dinâmica e mudança social dependem de uma série de fatores, atores e instituições que negociam e competem numa determinada dinâmica territorial.

Essa interpretação sobre os processos de mudança social está imbricada numa perspectiva orientada aos atores - POA desenvolvida em grande medida por um grupo de pesquisadores da universidade de Wageningen, Holanda. Essa perspectiva, como assinalam Arce, Blanco e

11 Estamos utilizando a noção de dinâmica territorial a partir de Marc Piraux para quem "As dinâmicas territoriais podem ser compreendidas como o resultado das interações entre os componentes econômicos, sociais, ambientais e espaciais do território. Nestes termos, a conformação dos territórios e sua evolução resultam das dinâmicas territoriais neles presentes, ao mesmo tempo que essas dinâmicas refletem as características próprias dos territórios. (CAZELLA, BONNAL, MALUF, 2009, p. 61). 
Hurtado (2008 p. 14), permite interpretações que levam em conta as experiências cotidianas dos atores sociais envolvidos, uma vez que as "investigações centradas nessa perspectiva permite ir além do aspecto discursivo ou textual das políticas, para nos centrar nas consequências empíricas da ação social" (tradução nossa).

A POA baseia-se no pressuposto de que atores sociais procuram resolver seus problemas, intervir nos seus cotidianos e monitorar suas práticas a partir de ações que lhes permitem fazer coisas ${ }^{12}$ capazes de causar mudanças em eventos preexistentes (ARCE, LONG, 2011). Essa capacidade de fazer coisas implica que esses atores sociais estejam envolvidos em uma rede de relações sociais e canalizem itens específicos por meio de certos pontos fundamentais de interação para que seus projetos sejam concretizados, adquirindo e construindo, assim, agência. Nesse sentido, adotar a POA pressupõe que se considere a ação dos agricultores na construção das mudanças e cenários específicos de vida.

Em termos empíricos, esse pressuposto direciona nosso olhar para as formas cotidianas nas quais os atores sociais direcionam seus projetos e interpretações acerca da realidade vivida. Os seus projetos são, de certa forma, direcionados pelo ambiente social em que estão imersos. Assim, os dispositivos utilizados para Sestão inseridos tanto numa teia de significados compartilhada socialmente quanto em circunstâncias condicionadas pela sua própria existência histórica e ambiental.

Esta perspectiva, portanto, nos leva a centrar esforços no entendimento do cotidiano das pessoas, na forma como estas negociam, a partir da sua realidade (que engloba também condições, necessidades e desejos), os "processos exógenos" (constrições estruturais como a mercantilização e a modernização da agricultura) com os "recursos endógenos" (capitais, conhecimento, experiência, condições ambientais, teia de significados, modos de vida, etc), construindo estratégias possíveis.

12 Fazer coisas - forma utilizada pelos autores para a expressão "Joint actions" (articulações). 
NesSa direção, a contribuição de Frank Ellis ${ }^{13}$ sobre as estratégias de vivência e da diversificação dos meios de vida adquire um valor interpretativo para as diversas realidades de desenvolvimento rural, pois a noção de diversificação pode ser definida como um "processo de construção de oportunidades pela família para sobreviver e obter melhor qualidade de vida" (PERONDI e SCHNEIDER, 2012, p. 124).

Para Ellis, as estratégias estão ligadas aos ativos (disponibilidade de capital natural, físico, humano, financeiro e social) ${ }^{14}$, às atividades desenvolvidas, ao contexto em que estas operam e às possibilidades de mudança a partir da ação dos atores, relacionadas também às constrições estruturais. Elas compreendem basicamente dois grandes tipos: as estratégias de escolha e adaptação e as estratégias de reação e necessidade.

Ambas as estratégias representam o resultado negociado entre a disponibilidade e a ordenação dos recursos produtivos e a ação dos atores que pode significar uma necessidade de sobrevivência ou uma forma de melhorar suas condições e são estes fins - necessidade de sobrevivência ou melhora de condições - e o contexto onde se inserem que, basicamente, diferencia os dois tipos de estratégias.

As estratégias de escolha e adaptação ocorrem a partir de uma reação voluntária e proativa por meio da construção de alternativas para aumentar as fontes de renda e de acessos a outros ativos. NesSe caso, pode ocorrer uma ascensão e até uma diferenciação social e econômica dos agricultores que conseguem mobilizar esse tipo de estratégias.

Por outro lado, as estratégias de reação e necessidade ocorrem num ambiente mais hostil que o anterior e são basicamente estratégias para continuar vivendo em contextos de crise. Por se darem em contextos mais hostis e serem parcos os ativos disponíveis, as estratégias possíveis se tornam mais escassas e reduzidas.

\footnotetext{
13 Para uma discussão histórica e crítica sobre a abordagem dos livelihoods centrada na questão dos ativos e acesso, recomendamos a leitura de Niederle e Grisa (2008) e Perondi e Schneider (2012).

14 Capital natural: terra, água e os recursos biológicos. Capital físico: criado no processo de produção e de vida das pessoas. Capital humano: educação, habilidades, saúde. Capital financeiro: condições financeiras e acesso crédito. Capital social: vínculos do indivíduo e do grupo doméstico com a comunidade. (PERONDI; SCHNEIDER, 2012)
} 
De qualquer forma, as estratégias possibilitam aos atores, apesar das inúmeras constrições estruturais e de ativos, a construírem projetos que permitem uma diversificação dos modos de vida, uma capacidade maior de reprodução social e "luta" por autonomia e liberdade.

Nesse sentido, ainda que em termos teóricos, podemos compreender a importância do PNCF como um programa que potencializa a capacidade dos atores em acessar a terra, importante ativo para a sua reprodução social e econômica, bem como aumentar as suas chances de desenvolver estratégias com maior autonomia e estar mais equipados para enfrentar crises. Quando se trata de disponibilizar uma linha específica para a juventude, esta importância adquire maior significado, haja vista a precariedade do acesso por parte deste grupo em específico.

Portanto, a adoção da perspectiva das estratégias assume valor substancial em nossa interpretação, pois permite relacionar a agência dos atores aos condicionantes estruturais (SCHNEIDER, 2003), mas não só isso, permite ainda visualizar uma dimensão mais subjetiva, de construção de projetos e trajetórias a partir de representações e interpretações que dizem respeito às histórias de vida.

Nesse sentido, o PNCF transforma-se, ele mesmo, num importante ativo, haja vista que irá compor um recurso fundamental na formação de alternativas para os jovens que desejam permanecer no campo. Tal acepção está de acordo com as argumentações de Niederle e Grisa (2008), "os ativos são ao mesmo tempo inputs e outputs das estratégias. Eles compõem a base dos recursos necessária à formação das alternativas de sobrevivência, as quais podem retroalimentar a plataforma de ativos" (NIEDERLE e GRISA, 2008, p.53).

Quando os jovens acessam a terra a partir do PNCF, esta transforma-se num ativo; contudo, o seu significado, seja enquanto ativo ou estratégia para permanecer no campo ou mudar de vida, ligase às trajetórias e histórias de vida das famílias. Essa acepção interpretativa, permite, portanto, focalizar tanto a dimensão objetiva do acesso aos ativos propostos na perspectiva mais usual quanto captar os significados que os ativos e as estratégias de vida assumem dentro das inúmeras trajetórias de vida marcadas por diferentes relações de poder e de acesso desigual aos recursos materiais. 
Com esse nivelamento teórico e a clarificação do método de coleta de dados adotado no estudo, estamos com mais condições de seguir aos resultados e possíveis discussões, assunto que se segue na próxima seção.

\section{Resultados e discussão}

\subsection{A operacionalização do PNCF}

Como vimos, a institucionalidade e a execução do PNCF são descentralizadas, num arranjo que congrega instituições públicas, organizações não governamentais e instituições privadas, além dos conselhos de desenvolvimento rural. Esse arranjo permite que haja diferenças estaduais e regionais de execução, sobretudo com relação ao encaminhamento e elaboração dos projetos.

No Brasil, no período de 2003 a 2013, foram realizadas 42.146 operações de PNCF, sendo a maior parte da linha CAF. O Espírito Santo, proporcionalmente, é o estado da região sudeste do Brasil que mais realizou operações de PNCF de 2003 a 2013. Foram 561 operações e 2.597 famílias.

Quanto ao número de operações de NPT, não dispomos de dados sobre o Brasil num período maior, pois no Painel de Indicadores (2014) as informações sobre essa linha só aparecem a partir de 2013, quando o NPT se torna uma linha de financiamento. De qualquer forma, o que nos parece importante é a constatação de que aproximadamente $35 \%$ dos participantes do PNCF têm até 28 anos de idade ${ }^{15}$, mostrando que o PNCF é um importante instrumento de aquisição de terra por parte dos jovens.

Os números do Espírito Santo, repassados pela UTE do estado, nos informam que, de 2004 a 2013, foram operacionalizados 35 projetos com o selo NPT, ao passo que o painel de indicadores nos informa que no estado, no mesmo período, foram feitas 561 operacionalização de PNCF16.

\footnotetext{
15 Se somarmos com a faixa etária que vai até os 32 anos de idade teremos $45 \%$ do total de participantes nessas duas faixas.

16 O que equivale a menos de $10 \%$ de operações de NPT, num estado no qual, segundo dados d o PNCF, 35\% das operações são feitas para jovens com até 28 anos de idade.
} 
Um dos questionamentos feitos neste artigo é por que, apesar de existir uma linha de financiamento específica para jovens, os mesmos preferem as outras linhas ${ }^{17}$ ? Embora não possamos generalizar, nossas conclusões para todos os casos do Brasil, quando questionamos os jovens sobre esses dados, as respostas estavam vinculadas com as opções trazidas pelos mediadores, ou seja, pelos técnicos das empresas que apresentavam a melhor proposta dentro das suas realidades.

Para um dos operadores do Programa e técnico de uma das empresas, a orientação para os jovens deve ser aquela que atende a melhor opção dentro das suas necessidades. Ele informou que costuma fazer um cálculo para ver se vale mais a pena pegar o bônus do NPT ou os juros menores do CPR, por exemplo. Com os cálculos prontos, apresenta a melhor opção dentro das linhas existentes.

Nesse sentido, compreendemos que se trata de cálculos, opções, mediações e decisões que demonstram uma racionalidade voltada para a minimização dos custos e maximização das oportunidades. Por outro lado, os próprios jovens pareciam desconhecer o programa como um todo, tendo uma visão parcial do seu projeto e dos motivos da sua inserção no NPT.

Com relação aos trâmites dos projetos, todos os jovens entrevistados colocaram como maiores problemas a demora na liberação dos recursos 18 e nas inúmeras idas e vindas do processo, na exigência de documentação e nos custos até o processo ser finalizado. A demora nos trâmites dificulta 0 acesso à terra, pois muitos proprietários desistem da venda haja vista a demora; por outro lado, as idas e vindas do processo estão ligadas, também, às mudanças de coordenação na Unidade Técnica Estadual - UTE.

Um ponto de destaque na nossa pesquisa refere-se ao processo de informação e mediação. Os entrevistados informaram que ficaram sabendo da existência do PNCF por meio dos técnicos de empresas

\footnotetext{
17 Em 2013, por exemplo, foram realizadas 932 operações somadas, CAF, CPR e NPT. Destas, apenas 12 operações foram NPT. Por outro lado, 35\% dos participantes do PNCF tinham até 28 anos de idade.

18 Nenhum projeto demorou menos de seis meses para ser concluído. Há casos de projetos que levaram até 15 meses para serem finalizados. Atualmente, há uma expectativa de demora de até 24 meses ou mais para finalização dos projetos. Não só os jovens colocam a demora como um problema, mas os próprios técnicos das empresas, o que poderia levá-los a abandonar o programa como linha de trabalho.
} 
privadas que fazem os projetos ou por meio de conhecidos (agricultores, parentes que moram na cidade e até mesmo os interessados em vender a terra). Esse dado revela a fragilidade do programa e dos próprios agricultores.

Sendo a informação um importante ativo, percebemos aqui um possível entrave entre o programa e o público-alvo, que repercute na própria eficiência. O Estado, embora tenha pensado um arranjo descentralizado capaz de ter uma maior capilaridade, não está sendo capaz de fazer chegar aos possíveis beneficiários informações que podem se tornar importantes estratégias de vida.

Quanto à mediação, os projetos foram todos elaborados por instituições privadas de Assistência Técnica e Extensão Rural - ATER. Da mesma forma, a assistência técnica é disponibilizada pela empresa que elaborou o projeto. Não houve nenhuma informação sobre a atuação dos sindicatos, ONG e mesmo empresas públicas de ATER na elaboração e condução dos projetos e na prestação de serviços de ATER.

Nesse sentido, quanto à operacionalização do programa, é possível apontar e levantar algumas considerações gerais: em primeiro lugar a questão do acesso dos jovens ao programa não se dá unicamente pelo NPT, mas por outras linhas de financiamento, quando estas se apresentam mais interessantes. Em segundo lugar, a questão do acesso à informação e ao conhecimento do programa nos parece um grande problema, uma vez que se nota uma possível seletividade nos beneficiários. Em terceiro lugar e relacionado ao segundo, está a questão da mediação, embora seja pensado um processo descentralizado, em rede, com a participação de inúmeras instituições, o que se percebeu com as entrevistas foi a exclusividade de projetos elaborados por empresas privadas, que dependem da lógica do mercado para atuar. O grande perigo desta última constatação é a ausência de outras instituições que não estão orientadas pelo mercado estarem deixando de cumprir suas funções sociais e de atingirem um público muitas vezes mais vulnerável.

\subsection{Percepções sobre mudanças e reflexões das escolhas}


Esta seção trata de aspectos levantados a partir dos questionários e mesmo das entrevistas realizadas. São apresentadas nesse formato para permitir melhor compreensão dos temas em questão.

Os questionários aplicados tinham como objetivo captar questões mais objetivas que, muitas vezes, não aparecem nas entrevistas, mas que são importantes por nos fornecerem informações de aspectos importantes da vida das famílias. Por outro lado, o questionário tinha uma série de questões que foram pensadas para captar as percepções acerca da mudança, entender como os próprios jovens estavam percebendo as mudanças após o PNCF.

A ferramenta foi dividida em seis temas: 1) característica dos domicílios; 2) produção, comercialização e consumo; 3) uso de tecnologias; 4) acesso a programas e políticas públicas; 5) trabalho e 6) percepções acerca da mudança.

a) características dos domicílios: Em termos gerais, são poucas pessoas residentes por domicílio. A família que apresenta maior número de pessoas residindo no mesmo local possui cinco membros. Não se constatou a existência de duas famílias morando numa mesma residência. A preferência pela ocupação do imóvel existente na propriedade é do jovem recém-casado ou os pais, quando estes já o ocupavam. Outra observação é o baixo número de pessoas com até 14 anos (as 4 pessoas abaixo de 14 anos têm menos de 9 anos). Observase a predominância de homens, salvo as mães e as mulheres casadas. Somente uma mulher solteira fazia parte de uma associação e residia no campo. Todos os domicílios eram de alvenaria, possuíam água, luz e banheiro dentro de casa.

b) produção, comercialização e consumo: com exceção de um projeto que produz apenas pecuária leiteira, todos os demais produzem café para a comercialização, ocupando a maior parte da área cultivada, mostrando uma grande especialização, relação com o mercado e adoção de tecnologias específicas à cultura. Dentre os que produzem café, seis também produzem leite visando ao mercado. Com relação à produção para consumo da família, esta aparece em $50 \%$ dos questionários, com a criação de pequenos animais (porcos, galinhas, patos), hortas, frutas, mandioca, feijão, milho e verduras em geral. Em uma associação, percebemos uma produção mais diversificada visando aos mercados institucionais e convencionais. Esta associação, além da produção do 
café e de subsistência, destaca-se das demais por agregar valor aos produtos, beneficiando a mandioca (farinha e polvilho), o urucum (colorau) e a cana-de-açúcar (melado).

Esse ponto é importante não só para o entendimento dos projetos dos jovens, mas para refletir acerca das promessas de projetos alternativos de desenvolvimento para a região. Nesse sentido, não é possível concluir que os jovens estejam procurando alternativas para a pouca diversificação da região ou mesmo preocupados com a questão da segurança alimentar e nutricional. Não há nenhuma expectativa por parte deles de se contraporem ao modelo hegemônico da região.

c) uso de tecnologia: em relação a utilização de algumas tecnologias, observamos que $70 \%$ usam irrigação; $100 \%$ utilizam adubação química, ao passo que apenas $40 \%$ utilizam adubação orgânica e somente um entrevistado declarou fazer uso de sementes crioulas. Com relação à mecanização, dois declaram utilizar trator tobata e capineira e um utiliza ordenhadeira mecânica.

d) acesso a programas e políticas públicas: $70 \%$ consideram que o fato de terem acessado o PNCF não os beneficiaram no acesso a programas e políticas públicas. Quatro entrevistados já acessaram o Programa de Aquisição de Alimentos - PAA, mas atualmente estão sem projetos. Dois acessam o bolsa família.

e) trabalho: de uma forma geral, percebemos um misto de estratégias de trabalho que podem ser divididas em três configurações: quatro trabalham na propriedade e na propriedade dos pais; três trabalham no estabelecimento e fora; três trabalham somente no estabelecimento. Essas diferentes configurações de trabalho sinalizam para uma diversificação dos meios de vida, por outro lado, mostram a vulnerabilidade ainda existente mesmo sendo proprietários de terra. Os entrevistados que trabalham fora sinalizaram a vontade de poder dedicar-se unicamente a sua propriedade (deles e/ou dos pais), vendo esta situação como algo transitório até melhorarem as condições.

f) percepções acerca da mudança: de um modo geral, todos os entrevistados consideram que a condição de suas vidas melhorou após o PNCF. Perguntados sobre a situação econômica e qualidade de vida, $100 \%$ perceberam melhoras. Com relação à participação política e cultural, não houve grandes mudanças, apenas três pessoas perceberam melhoras, como maior participação em reuniões e maior acesso a 
informações e políticas públicas. Questionados sobre a melhora nas condições de saúde e alimentação e nutrição, cinco entrevistados perceberam mudanças. Com exceção de uma pessoa, a condição de trabalho e produção, depois do PNCF, melhorou.

Em termos gerais, os questionários auxiliaram a conhecer a realidade mais objetiva, o momento atual. Nesse sentido, proporciona uma fotografia da situação das famílias, suas formas de trabalhar, produzir e comercializar, bem como a percepção de que suas vidas melhoraram depois do PNCF.

3.3 Trajetórias de vida, estratégias e projetos de futuro: a importância e o significado da terra em diferentes tipos de agricultores

Conhecer as trajetórias de vida das pessoas, contada por elas mesmas, nos permite compreender as estratégias adotadas, possíveis e desejadas dentro de várias contingências. Na POA, as narrativas assumem uma importância fundamental no entendimento de uma realidade, pois a forma como as pessoas contam a história e explicam e/ou justificam suas escolhas está permeado de uma série de representações, relações e interações que lhes permitem dar um significado a sua realidade e as suas práticas.

Nesta seção, apresentam-se os elementos que permitem inferir a respeito da importância que a terra assume na vida dos jovens ouvidos no estudo, bem como mapear diferentes tipos de estratégias que levaram os beneficiários a procurar o PNCF e as que, atualmente, utilizam para permanecer no campo.

As sete entrevistas coletivas realizadas com as associações de PNCF foram feitas nas respectivas propriedades, com a participação dos jovens e familiares. Ao todo, participaram 20 pessoas envolvidas diretamente com os processos de aquisição da terra, bem como relacionado ao trabalho atual ${ }^{19}$.

\footnotetext{
19 As entrevistas seguiram um formato dialógico que permitiu o estabelecimento de uma conversa entre todos. No momento da apresentação do projeto e dos objetivos da pesquisa, explicamos que o roteiro existia só para orientar o tema da conversa, mas que todos estavam convidados a participar do diálogo, ficando à vontade para colaborar e intervir da forma que achasse melhor. Assim, participaram não só os jovens responsáveis pelo projeto, mas demais familiares presentes, como pai, mãe, cônjuge.
} 


\subsubsection{Diferentes trajetórias, distintos tipos de estratégias}

A partir das entrevistas, é possível numa sistematização da realidade ${ }^{20}$, mapear dois grupos de agricultores existentes entre os entrevistados. Nossa opção foi realizar essa sistematização a partir dos elementos que foram apresentados como motivação para a escolha do PNCF e o significado atribuído à terra.

O primeiro grupo é formado por ex-meeiros ${ }^{21}$. Para esse grupo, formado por três associações, a aquisição da terra representa um divisor de águas em suas vidas. Para eles, fica fácil contrapor uma vida antes do PNCF e a atual. A terra representa mudança de vida, autonomia, liberdade e segurança, além de uma vida com mais recursos.

Com relação às lembranças negativas, os filhos de meeiros relembram os momentos de falta de autonomia, de incertezas, de falta de liberdade e insegurança, o que nos leva a perceber a vulnerabilidade social e econômica na qual estas famílias estavam inseridas. Desse modo, do nosso ponto de vista, a aquisição da terra pelo PNCF mais do que uma estratégia de aumento de renda, foi uma estratégia de reação num ambiente hostil, no qual as condições de sobrevivência estavam se tornando insustentáveis e o êxodo era um último recurso, tema presente em quase todas as falas deste grupo.

Essa ideia ganha mais coerência quando ouvimos as falas dos agricultores sobre as lembranças negativas que guardam antes do acesso ao PNCF e sobre a importância de ter uma propriedade 22 .

Trabalhar de meia, nunca mais![se referindo a pior lembrança]. Trabalhava, trabalhava e pegava aquele pouquinho. Um ano era bom, no outro ano o patrão já começava. O primeiro ano tudo tá bom, depois começa querer, faz isso, faz aquilo. No final do ano é difícil. (...) Não tem jeito, tem que pagar a metade de

\footnotetext{
20 No anexo dois incluímos um compêndio sobre esses dois grupos.

21 Meeiro é uma relação de trabalho, muito comum ainda no Brasil, na qual a relação de trabalho é baseada no trabalho do meeiro que em troca dos meios de produção do proprietário da terra (patrão) deixa, na maioria das vezes, $50 \%$ dos resultados do seu trabalho.

22 Como especificado na parte metodológica, as falas trazidas no texto são identificadas por associação e não por pessoa, pois recortamos mais de um interlocutor por associação.
} 
tudo. Pra ele fica bom, pra gente não. Pra ele fica aquele montão (Associação 5, Águia Branca, 22/05/2014).

Morar em cima da propriedade dos outros [se referindo a pior lembrança]. Não quero ser mandado como eu era antes. (...) $\mathrm{O}$ patrão falou que então eu podia deixar a casa que ia procurar outro para ocupar a terra. E isso eu não quero passar nunca mais, ser mandado assim. Morar na propriedade de outro e ser mandado. Pra mim eu não quero. Não aconteceu isso comigo, mas com meu pai aconteceu. (...) Quando pede para fazer alguma coisa, tem que fazer porque não é dono. O que eu não quero é isso. (...) Não quero passar o que meu pai passou na terra dos outros. (...) Não quero trabalhar para os outros. Trabalhar aqui e tirar daqui, sem precisar ficar trabalhando para a pessoa e ouvir que o serviço não tá bom! Essas coisas que não quero viver (Associação 6, Barra de São Francisco, 22/05/2014).

Não queria deixar minha mãe e meu pai sofrendo em colônia dos outros. Coloquei eles no meu pedaço de terra. Sofri demais na colônia dos outros, Nossa Senhora! Nós sofríamos muito. (...) Trabalhava a dia para os outros para comprar as coisas para dentro de casa. Nossa senhora! O patrão chegava com o caminhão e levava o café para o secador e dava tantas sacas e dava o dinheiro. (...) Meu pai largou arroz na hora de cortar, feijão na hora de tirar, tudo para o patrão. (...) Pai, não aguento mais essa vida, vou mexer na terra do Pronaf (Associação 7, Barra de São Francisco, 23/05/2014).

Se estas falas sobre as lembranças negativas e sobre as coisas que não querem voltar a viver nos dão a noção da centralidade da argumentação em torno da terra, as respostas quanto ao maior tesouro que possuem agora corrobora nossas interpretações acerca do significado do possuir a terra enquanto liberdade, autonomia e segurança.

Desse modo, transcrevemos as falas sobre o maior tesouro que possuem agora.

Ah, é estar em cima do que é nosso. Hoje se a gente quiser trabalhar, trabalha, se não quiser não trabalha. Quando morava de meia tinha que trabalhar todo dia. Tinha que estar a tempo e a hora. Tinha que aguentar bucha que a gente aguentava. (...) Nós estamos tudo aqui em cima (da terra). Ter um lugar para a gente sair e voltar. Quando a gente mora de meia, talvez um ano sabia que ficava, outro ano não sabia se ficava mais lá. Hoje não, hoje tá aqui em cima. Ficava um tempo num lugar, saía e ia para outro. Aqui não, aqui eu espero que fique muito 
tempo. Primeiro colhia um saco de feijão e tinha que dividir no meio. Hoje não, se colhe um saco é nosso, se colhe meio é nosso (Associação 5, Águia Branca, 22/05/2014).

Ter a terra e viver em cima dela. Tirar o sustento dela para não ficar trabalhando para outros. Estou tranquilo! Não penso em que amanhã preciso ter um caminhão para puxar minha mudança. Estar tudo unido num lugar só, que é da gente. (...) Hoje consegue pensar no futuro. Ir fazendo. Hoje a gente pensa se vai trabalhar para os outros. Hoje pode fazer um plano para o futuro. Pode fazer projeto para o café. Aqui pode pensar que vai plantar e daqui a três anos vai colher. Antes não podia. Tinha que fazer o que deixavam a gente fazer. O principal já tem, que é a terra. É ter coragem de trabalhar e trabalhar. Será que um dia vou conseguir comprar $1 / 2$ alqueire? Ai já parava de pensar no futuro. Aqui se eu plantar 1.000 pés de café é o que vou esperar dele. É o meu projeto! Já o projeto que o patrão tem, ele manda a gente fazer para ele, ele vem depois e diz que tem que arrancar o café para plantar capim. E tem que arrancar o café e receber o dia. (...) E o que não der certo, pode desmanchar, mas é a gente que decide. Primeiro Deus, depois a gente. Quando é meeiro pensa em fazer, mas o patrão pensa de outro jeito (Associação 6, Barra de São Francisco, 22/05/2014).

Meu pai está tranquilo. Dorme a hora que quer, trabalha a hora que quer. A gente tá aqui, tá tranquilo. Ninguém tira a gente daqui. Agora estou dentro da minha terrinha. O café já deu dinheiro para pagar a terra (Associação 7, Barra de São Francisco, 23/05/2014).

Para esse grupo, a lembrança negativa da vida de meeiro é contrastada com a autonomia de quem vive e trabalha "em cima" do que é seu, o que lhe permite pensar no futuro, ter um projeto que é verdadeiramente seu. Importante identificar que esses projetos de futuro contam com os pais, portanto, é também um projeto imbuído da lógica familiar.

O segundo grupo é formado por quatro associações. São filhos de proprietários que argumentam a centralidade da terra como forma de aumento de segurança, reprodução social e qualidade de vida. Assim, as estratégias do tipo de escolha e adaptação se desenvolvem num ambiente de precário acesso à terra, mas que, ainda assim, é um contexto no qual as pessoas têm um espaço de maior autonomia e segurança. 
Quando questionados sobre a motivação para a escolha pelo PNCF, as falas revelam nitidamente esses aspectos.

Não tinha dinheiro para comprar a terra. (...) [Queria] ficar na roça, não ter que sair. Crescer cada vez mais. Crescer a área mais. (...) Não tinha dinheiro, precisei entrar no crédito para conseguir comprar. (...) Nós [ele e os irmãos] estávamos junto com o pai. O que é dele [do pai] é nosso. (...) Então nós temos que pensar em crescer o patrimônio, porque futuramente é nosso também. Não tem para outro, com certeza é nosso (Associação 1, Águia Branca, 22/05/2014).

A gente não tinha condições de comprar a terra. Surgiu a terra para comprar. A gente animou porque meu pai mora aqui [vizinho da terra]. A terra era do meu tio. (...) E acrescentar a área. (...) No pensamento da gente é terra, é o que a gente sabe fazer e gosta de fazer. (...) Comprar mais um pedaço, aumentar. Se ele casa, ele casa, o terreno vai ficar pequeno. Aumentar e produzir mais (Associação 2, Águia Branca, 23/05/2014).

Porque na época não tinha condições para comprar a parte dos irmãos do pai e a única solução era o PCNF. Eram oito irmãos para quatro alqueires e meio. O que oito irmãos iam fazer com quatro alqueires? E na época não tinha condições de comprar. Não dava para ficar com 2.5 hectares (Associação 3, Águia Branca, 23/05/2014).

Primeiro é que pela divisão dava 8.9 hectares era pouco para trabalhar. Ai ficou um pouco mais terra para trabalhar e maior segurança pra gente também (Associação 4, Águia Branca, 23/05/2014).

Observa-se a centralidade nas argumentações sobre a escassez da terra e a necessidade de aumentar o patrimônio. No entanto, é preciso atentar para o fato que dos quatro projetos aqui trazidos, três são confinantes dos pais ${ }^{23}$. A terra à venda era dos tios, resultado de um processo de partilha dos avós falecidos. Dessa forma, a lógica da argumentação desses jovens revela não só um projeto individual, mas uma lógica familiar, inclusive de agregação e bem-estar dos pais (da família como um todo) por meio do aumento do patrimônio.

Mas aumentar o patrimônio não tem apenas um significado econômico, pelo contrário, é também condição de reprodução dos meios de vida das famílias. Nas falas anteriores, ficou evidente a

230 outro projeto que não era confinante do pai, estava a menos de 500 metros de distância da terra dos pais. 
insustentabilidade e a inviabilidade de reprodução nas condições de escassez de terra. Aumentar a terra, portanto, era a condição de permanência não só dos jovens, como também dos mais velhos.

O que é central nessas argumentações é uma lógica centrada na aquisição de mais terra para a possível reprodução da família, aumento de renda, segurança e permanência no campo. O PNCF, nesse sentido, significa uma capacidade de crédito, sem o qual não teriam condições de aumentar o patrimônio familiar e garantir a reprodução social e a permanência no campo.

Seja como for, claro está que as narrativas estão alicerçadas na tríade terra, trabalho e família, presente como sistema integrado da lógica produtiva e reprodutiva da agricultura familiar (WANDERLEY, 1999). As decisões dos atores sociais repercutem, portanto, tanto a lógica da agricultura familiar quanto os elementos estruturais de precário acesso à terra.

Dessa forma, o PNCF, para esses jovens, torna-se não só uma estratégia para sua permanência no campo, mas uma alternativa que permite a manutenção e o aumento da propriedade familiar.

Com relação ao significado da terra, esta é muito importante, mas por serem filhos de proprietários, ela já cumpria seu papel de autonomia e liberdade. Faltava, no entanto, terra suficiente para a garantia dessa autonomia, a reprodução da família e a segurança que se traduz em melhoria de vida.

Questionados sobre o maior tesouro na atualidade, percebemos a importância da terra presente na fala de todos os entrevistados.

Poderia até falar a terra, mas hoje sou pai, então é minha menina. Quando não tinha minha menina, era a terra. Porque como a gente fala, é onde vou construir minha família (Associação 1, Águia Branca, 22/05/2014).

É a terra, nosso suor. Estamos pagando com nosso suor. Mais valioso é a terra e estamos trabalhando em cima dela. Nunca acaba, é pro resto da vida (Associação 2, Águia Branca, 23/05/2014).

A terra, né. Se o café não valer nada, você arranca e planta outra coisa. Tendo a terra para trabalhar, é melhor do que trabalhar de empregado (Associação 3, Águia Branca, 23/05/2014).

Tranquilidade de poder trabalhar. Ter a terra. Ter a segurança que pode plantar, ter os projetos. Ter a tranquilidade de poder 
trabalhar. É o cantinho nosso, a terra, os familiares (Associação 4, Águia Branca, 23/05/2014).

A terra aparece central nas argumentações desse grupo. Primeiro, por ser concreta, duradoura, permanente. É nela que se constrói a família, trabalha-se, realizam-se os projetos e se dão as principais relações sociais. A tríade presente na lógica da agricultura familiar não podia estar melhor representada do que nessas falas.

De qualquer forma, tanto para os jovens do primeiro quanto do segundo grupo, observamos a lógica familiar presente nas suas estratégias. No primeiro grupo, os pais foram inseridos nos projetos do PNCF, seja como associado, seja como integrante ativo das atividades produtivas do programa e mesmo dos projetos de futuro. A diferença, no entanto, está na própria importância do PNCF: para o caso dos exmeeiros, a terra significava também uma condição de autonomia para os pais, no caso dos proprietários, uma forma de aumento da renda e do próprio patrimônio.

\section{Considerações finais}

As opções teóricas adotadas neste artigo e as narrativas dos atores sociais sobre suas opções e estratégias, possibilita-nos compreender as atitudes dos jovens que optaram por permanecer no campo, tendo na aquisição da terra a centralidade das suas argumentações e interpretações, tanto como estratégia de escolha e adaptação quanto de reação e necessidade.

A luta constante pelo fortalecimento da base de recursos disponíveis e a capacidade de luta constante por autonomia e liberdade presentes na agricultura familiar (PLOEG, 2008) nos permite identificar, nas narrativas dos jovens entrevistados, que a escolha pelo PNCF representa um importante espaço de manobra em face ao precário ou ausente acesso à terra, não só pelo jovem, mas por toda a sua família, num histórico processo desigual de acesso aos meios de produção.

$\mathrm{O}$ acesso ao PNCF, por meio do NPT, representa, portanto, a capacidade dos jovens em acessarem o principal ativo de reprodução social e econômica da sua condição de agricultor, bem como da sua possibilidade de construir projetos mais autônomos e legitimar a sua 
importância enquanto um ator social que emerge com anseios e projetos próprios no campo brasileiro.

Há que se observar, por fim, que entre os dois grupos se trata de realidades e trajetórias diferentes de acesso à terra e de condições de vida. As restrições estruturais estão presentes em ambos os casos e mostram que se deve estar atento às implicações destas, contudo, ao analisarmos as possibilidades de mudanças a partir dos atores sociais, verificam-se diferentes conformações, das capacidades individuais e do papel fundamental das politicas públicas para diminuir as desigualdades e propor alternativas de desenvolvimento rural.

\section{REFERÊNCIAS}

ARCE, A; BLANCO, G.; HURTADO, M. (Ed.). Politicas públicas como objeto social: imaginando el bien público em el desarrollo rural latinoamericano. Guatemala: Flacso; Chile: Universidad Austral de Chile; Holanda: Wagenigen University, 2008.

LONG, N. ; ARCE, A. Heterogeneidade, ator e estrutura: para a reconstituição do conceito de estrutura. In: SCHNEIDER, S.; GAZOLLA, M. (Org.) Os atores do desenvolvimento rural. Porto Alegre: UFRGS, p. 21 $48,2011$.

BRASIL, Ministério Desenvolvimento Agrário. Manual de operações do CPR-SIB, CAF e NPT. Brasília, 2013.

BRASIL, Ministério Desenvolvimento Agrário. Painel de Indicadores Gerenciais da Secretaria de Reordenamento Agrário, Boletim Ano IX, Edição 04/2014. Brasília, 2014.

CAMARANO, A. A.; ABRAMOVAY, R. Êxodo rural, envelhecimento e masculinização no Brasil: panorama dos últimos 50 anos. Encontro Nacional sobre Migração. Curitiba. Anais..., Curitiba, 1997. Disponível em

<http://www.abep.nepo.unicamp.br/docs/anais/outros/1 EncNacSobre Migracao/AnaisENSMigracaoCuritiba1997p303a327.pdf>. 
CASTRO, A. M. G. et al. Juventude rural, agricultura familiar e políticas de acesso à terra no Brasil. Brasília: Ministério do Desenvolvimento Agrário, 2013.2 Disponível em: <http://www.nead.gov.br/portal/nead/nead-estudos>

FROEHLICH, J.M. et al. Êxodo seletivo, masculinização e envelhecimento da população rural na região central do Rio Grande do Sul. Ciência Rural. Santa Maria, v.41, n.9 p.1674-1680, 2011.

LIMA, D. F. P. Avaliação do impacto do Programa Nacional de Crédito Fundiário na região sul do Brasil. 2011. 141f. Dissertação (Mestrado em Ciências) - Universidade de São Paulo, Piracicaba, 2011.

NIEDERLE, P.A; GRISA,C. Diversificação dos meios de vida e acesso a atores e ativos: uma abordagem sobre a dinâmica de desenvolvimento local da agricultura familiar. Cuadernos Des. Rural. Bogotá (Colombia), v. 5, n. 61, p. $41-69,2008$.

PERONDI, M.A.; SCHNEIDER, S. Bases teóricas da abordagem de diversificação dos meios de vida. REDES. Santa Cruz do Sul, v. 17, n.2, p. 117-135, 2012.

PLOEG, J.D. Camponeses e impérios alimentares: lutas por autonomia e sustentabilidade na era da globalização. Porto Alegre: UFRGS, 2008.

SCHNEIDER, S. A pluriatividade na agricultura familiar. Porto Alegre: UFRGS, 2003.

WANDERLEY, M. N. B. Raízes históricas do campesinato brasileiro. In: TEDESCO, J.C. (Org.). Agricultura familiar: realidades e perspectivas. Passo Fundo: EDIUPF, 1999.

WANDERLEY, M. N. B. Jovens rurais de pequenos municípios de Pernambuco: que sonhos para o futuro. In: CARNEIRO, M. J; GUARANA, E C. de. Juventude rural em perspectiva. Rio de Janeiro: Mauad X, 2007. 
Entre trajetórias e estratégias de vida: a importância do Programa Nacional de Crédito Fundiário...

Aprovado em02/08/2016

\section{Celia Jaqueline Sanz Rodriguez}

Doutoranda (PGDR/UFRGS), agente desenvolvimento rural do Incaper, bolsista FAPES.

E-mail: jaqueline.sanz@ufrgs.br

\section{Marcelo Antonio Conterato}

Doutor em desenvolvimento rural, professor do Departamento de Economia e Relações Internacionais - DERI e do Programa de Pós-Graduação em Desenvolvimento Rural PGDR e Coordenador do Bacharelado em Desenvolvimento Rural (Plageder), ambos da UFRGS.

E-mail: marcelo.conterato@ufrgs.br 


\section{ANEXOS}

\begin{tabular}{|c|c|c|c|c|c|}
\hline \multicolumn{6}{|c|}{ Anexo 1. Quadro das linhas de financiamento do PN } \\
\hline $\begin{array}{l}\text { Linha de } \\
\text { crédito/sel } \\
\text { o }\end{array}$ & Juros/ano & $\begin{array}{l}\text { Renda anual } \\
\text { familiar }\end{array}$ & $\begin{array}{l}\text { Limite de } \\
\text { crédito/beneficiá } \\
\text { rio }\end{array}$ & $\begin{array}{l}\text { Recursos para } \\
\text { ATER }\end{array}$ & $\begin{array}{l}\text { Prazo do } \\
\text { financiamento }\end{array}$ \\
\hline CPR & $0,50 \%$ & Até $\mathrm{R} \$ 9.000,00$ & $\mathrm{R} \$ 80.000,00$ & $R \$ 7.500,00$ & $\begin{array}{l}\text { Até } 20 \text { anos, } \\
\text { com } 3 \text { de } \\
\text { carência }\end{array}$ \\
\hline CAF & $2,00 \%$ & Até $R \$ 15.000,00$ & $\mathrm{R} \$ 80.000,00$ & $R \$ 7.500,00$ & $\begin{array}{l}\text { Até } 20 \text { anos, } \\
\text { com } 3 \text { de } \\
\text { carência }\end{array}$ \\
\hline NPT** & $1,00 \%$ & Até $R \$ 15.000,00$ & $\mathrm{R} \$ 80.000,00$ & $R \$ 7.500,00$ & $\begin{array}{l}\text { Até } 20 \text { anos, } \\
\text { com } 3 \text { de } \\
\text { carência }\end{array}$ \\
\hline \multicolumn{6}{|c|}{$\begin{array}{l}\text { Critérios gerais de elegibilidade para as linhas CPR e CAF: 1) ser trabalhador rural sem terra; ou } \\
\text { proprietário de imóveis cuja área não alcance a dimensão da propriedade familiar (Lei 4.504) e } \\
\text { seja comprovadamente insuficiente para gerar renda capaz de sustentar a família. 2) Não ter sidd } \\
\text { beneficiário do Programa de Reforma Agrária; 3) não seja funcionário público; 4) mínimo de } 5 \\
\text { anos de experiência com a exploração agropecuária; 5) não tenha sido, nos últimos } 3 \text { anos } \\
\text { proprietário de imóvel rural superior a área de propriedade familiar; 6) não tenha herança de } \\
\text { terra; 7) não tenha restrições cadastrais com agentes financeiros. Para o linha CPR, além de } \\
\text { preencher estes requisitos, o beneficiário precisa estar inscrito no Cadastro Único (CadUnico) } \\
\text { para programas sociais do governo federal. } \\
\text { ** A linha NPT concede um bônus de R\$ } 3.000 .00 / \text { beneficiário. }\end{array}$} \\
\hline
\end{tabular}

Anexo 2. Sistematização das associações de PNCF

\begin{tabular}{|c|c|c|c|c|}
\hline $\begin{array}{l}\text { Associaçã } \\
\text { o }\end{array}$ & $\begin{array}{l}\text { Ano do } \\
\text { projeto }\end{array}$ & $\begin{array}{l}\text { Tipo de agricultor } \\
\text { antes do PNCF }\end{array}$ & Importância do PNCF & Significado da terra \\
\hline 1 & 2007 & Filho de proprietário & \multirow{4}{*}{$\begin{array}{l}\text { Melhorar condição de } \\
\text { vida. Aumentar } \\
\text { patrimônio familiar. } \\
\text { Estratégia de escolha e } \\
\text { de adaptação. Poder } \\
\text { permanecer no campo. }\end{array}$} & \multirow{4}{*}{$\begin{array}{l}\text { Reprodução social. } \\
\text { Condição de agricultor. } \\
\text { Segurança. }\end{array}$} \\
\hline 2 & 2004 & Filho de proprietário & & \\
\hline 3 & 2004 & Filho de proprietário & & \\
\hline 4 & 2006 & Filho de proprietário & & \\
\hline 5 & 2006 & Filho de meeiro & \multirow{3}{*}{$\begin{array}{l}\text { Mudar de condição de } \\
\text { vida. Estratégia de } \\
\text { reação. Poder } \\
\text { permanecer no campo. }\end{array}$} & \multirow{3}{*}{$\begin{array}{l}\text { Autonomia, liberdade, } \\
\text { segurança. Condição de } \\
\text { agricultor. }\end{array}$} \\
\hline 6 & 2009 & Filho de meeiro & & \\
\hline 7 & 2008 & Filho de meeiro & & \\
\hline
\end{tabular}

